\title{
Cell adhesion and growth enabled by biomimetic oligopeptide modification of a polydopamine-poly(ethylene oxide) protein repulsive surface
}

\author{
Jana Musilkova $^{1} \cdot$ Ilya Kotelnikov ${ }^{2} \cdot$ Katarina Novotna $^{1} \cdot$ Ognen Pop-Georgievski $^{3}$ •

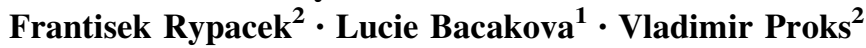

Received: 4 June 2015/Accepted: 21 September 2015/Published online: 8 October 2015

(c) The Author(s) 2015. This article is published with open access at Springerlink.com

\begin{abstract}
Protein-repulsive surfaces modified with ligands for cell adhesion receptors have been widely developed for controlling the cell adhesion and growth in tissue engineering. However, the question of matrix production and deposition by cells on these surfaces has rarely been addressed. In this study, protein-repulsive polydopamine-poly(ethylene oxide) (PDA-PEO) surfaces were functionalized with an RGD-containing peptide (RGD), with a collagen-derived peptide binding fibronectin (Col), or by a combination of these peptides (RGD $+\mathrm{Col}$, ratio 1:1) in concentrations of $90 \mathrm{fmol} / \mathrm{cm}^{2}$ and $700 \mathrm{fmol} / \mathrm{cm}^{2}$ for each peptide type. When seeded with vascular endothelial CPAE cells, the PDA-PEO surfaces proved to be completely non-adhesive for cells. On surfaces with
\end{abstract}

Jana Musilkova and Ilya Kotelnikov have contributed equally to this work.

Electronic supplementary material The online version of this article (doi:10.1007/s10856-015-5583-3) contains supplementary material, which is available to authorized users.

Lucie Bacakova

lucy@biomed.cas.cz

$\triangle$ Vladimir Proks

proks@imc.cas.cz

1 Department of Biomaterials and Tissue Engineering, Institute of Physiology of the Czech Academy of Sciences, v.v.i., Videnska 1083, 14220 Prague 4 - Krc, Czech Republic

2 Department of Biomaterials and Bioanalogous Systems, Institute of Macromolecular Chemistry, Academy of Sciences of the Czech Republic, v.v.i., Heyrovsky Sq. 1888/2, 16206 Prague 6, Czech Republic

3 Department of Chemistry and Physics of Surfaces and Biointerfaces, Institute of Macromolecular Chemistry, Academy of Sciences of the Czech Republic, v.v.i., Heyrovsky Sq. 1888/2, 16206 Prague 6, Czech Republic lower peptide concentrations and from days 1 to 3 after seeding, cell adhesion and growth was restored practically only on the RGD-modified surface. However, from days 3 to 7, cell adhesion and growth was improved on surfaces modified with $\mathrm{Col}$ and with RGD + Col. At higher peptide concentrations, the cell adhesion and growth was markedly improved on all peptide-modified surfaces in both culture intervals. However, the collagen-derived peptide did not increase the expression of fibronectin in the cells. The deposition of fibronectin on the material surface was generally very low and similar on all peptide-modified surfaces. Nevertheless, the RGD + Col surfaces exhibited the highest cell adhesion stability under a dynamic load, which correlated with the highest expression of talin and vinculin in the cells on these surfaces. A combination of RGD + Col therefore seems to be the most promising for surface modification of biomaterials, e.g. vascular prostheses.

\section{Introduction}

Cell adhesion and proliferation are crucial steps in cell cultivation and in various tissue engineering applications. On most conventionally used biomaterials, such as synthetic polymers, ceramics or metals, the cell adhesion is mediated by proteins adsorbed on the material surface from biological fluids, including serum-supplemented cell culture media, blood or interstitial fluid. The amount, the types and the geometrical conformation of the adsorbed proteins is regulated by the physical and chemical properties of the material surface, e.g. its wettability, electrical charge and conductivity or the roughness and topography [1, 2]. However, the control of the cell behavior is not fully 
precise and not fully defined using this approach. In addition, the use of entire protein molecules can evoke an immune reaction after the modified material is implanted into the organism, if these molecules are of allogeneic or xenogeneic origin.

An alternative approach, which can circumvent these problems, is based on surface material coatings that completely suppress the non-specific protein adsorption and consequently cancel out the non-specific cell/material interactions. Surface adherent non-fouling layers can be achieved by a reaction of the polymer-functionalized terminal group with the material surface ("grafting to"), or by surface initiated polymerization from a surface-bound reactive species ("grafting from"). Some of the most effective non-fouling layers are realized utilizing dense poly(ethylene oxide) (PEO) [3] and ethylene oxide-based brushes, peptides [4], poly(betaine) zwitterions [5] and $N$-(2-hydroxypropyl)methacrylamide [6]. Protein-repulsive surfaces carrying reactive functional groups can easily be modified with various biomimetic groups (for example, the well-known fibronectin-derived RGD peptide ligand) [7]. Widely used bioconjugative reactions are exemplified by the thiolene reaction of thioles with an activated double bond [8], the alkyne-azide cycloaddition reaction [9] (click chemistry) and native chemical ligation [10].

On the one hand, this approach allows exact studies of primal cell adhesion, proliferation and differentiation. The adhesion ligands can be attached to biomaterials in defined types, concentrations, spacing, random or ordered distribution etc., which enable much more precise control of the number of adhering cells, their spreading area, proliferation, the switch between proliferation and differentiation, phenotypic maturation and cell functioning than the spontaneously adsorbed entire protein molecules. On the other hand, it has been shown that an increased concentration of adhesion ligands on the material surface decreased extracellular matrix (ECM) production by the cells adhering to these scaffolds, which limits the application of these scaffolds in tissue engineering [11]. The synthesis of ECM by these cells can be increased by tethering the transforming growth factor-beta (TGF- $\beta$ ) on the material surface [12] or by adding soluble TGF- $\beta$ to the cell culture media [12]. However, protein-repulsive surfaces, used as a background for anchoring adhesion oligopeptides, allow no possibility or only a limited possibility of adsorbing the newly synthesized ECM molecules, even if their synthesis by cells is increased. This problem could be overcome by the use of oligopeptidic ligands not only to promote cell adhesion but also to anchor the newly synthesized ECM molecules to the material scaffolds.

In the present work, we therefore focused on the cultivation of vascular endothelial cells on non-fouling substrateindependent surfaces based on the polydopaminepoly(ethylene oxide) (PDA-PEO) system [13-16] allowing modification of any solid material. A combination of two different sorts of ligands was used for the biomimetic modifications. Specifically, fibronectin-derived ligands were used for integrin-mediated cell adhesion [17] and collagenderived peptide ligands, responsible for the specific collagen-fibronectin interaction [18], were used to anchor cellexpressed fibronectin to the material surface. These ligands were applied in two concentrations, i.e. 90 or $700 \mathrm{fmol} / \mathrm{cm}^{2}$ in order to find their appropriate concentrations for cell adhesion, growth and matrix synthesis and deposition.

On the newly developed surfaces, functionalized either with RGD-containing oligopeptides, collagen-derived and fibronectin-binding peptides, or with combinations of both ligands, the adhesion, growth and expression of the gene for fibronectin were studied in vascular endothelial cells of the CPAE line. The cell behavior was investigated not only in the conventional static culture system but also in a dynamic culture system, better mimicking the conditions to which the cells are exposed in vivo, e.g. shear stress. Increased stability of the endothelial layer during the dynamic cultivation in our study was expected due to the additional binding to the cell-expressed fibronectin network anchored to the protein-repulsive surface.

\section{Materials and methods}

Materials and methods used for the preparation of the model substrates, surface plasmon resonance (SPR) chips and cell seeding substrates are listed in Supporting Information.

\subsection{Peptide synthesis and radiolabeling}

Azidopentanoyl-GGGRGDSGGGY-NH $\mathrm{N}_{2}$ and azidopentanoylGGG-QRQVVGLOGQRGERGFOGLOG- $\mathrm{NH}_{2}$ (where O represents hydroxyproline) were prepared on solid phase using the standard Fmoc/tBu protocol, as described previously [19]. The azidopentanoyl-GGGRGDSGGGY-NH peptide for the model surface modification reaction was radiolabeled on solid phase according to Mackova et al. [20]. Peptide synthesis, peptide radiolabeling, substrate modification and a radioassay to determine the exact peptide surface concentration were performed according to Proks et al. [19]. The relationship between ligand distance and concentration was calculated according to hexagonal model proposed by Dalsin et al. [21].

\subsection{Preparation of the protein-repulsive surface}

The protein repulsive substrates were prepared according to procedure described by Lee et al. [13]. The PDA coated surfaces were rinsed with copious amounts of $\mathrm{H}_{2} \mathrm{O}$, were sonicated in $\mathrm{H}_{2} \mathrm{O}$ for $15 \mathrm{~min}$ to remove non-specifically 
bound microparticles and were dried in $\mathrm{N}_{2}$ gas. The PDA surfaces were stabilized by thermal annealing for $24 \mathrm{~h}$ at $110^{\circ} \mathrm{C}$ before the PEO grafting procedure [22]. The average thickness of PDA-PEO layers determined by ellipsometry was $16.2 \pm 3.1 \mathrm{~nm}$ for PDA and $12.7 \pm 3.9 \mathrm{~nm}$ for PEO respectively. The same procedure was applied for the round microscopic glass coverslips (Menzel-Gläser, Germany, diameter $12 \mathrm{~mm}$, \#1, thickness $0.13-0.16 \mathrm{~mm}$ ) for the cell culture studies. See Supporting Information for the detailed description of the procedure.

\subsection{Biomimetic modification of substrates}

Biomimetic modification of the substrates was performed according to a previously described procedure [19]. Briefly, forty microliters of the reaction mixture containing peptide solution, copper sulfate and sodium ascorbate were dropped on Parafilm and were covered with the PEO-coated side of the glass slide. The substrates were incubated for $15 \mathrm{~min}$ and washed three times with Milli- $Q$ water. The concentration of immobilized peptides was determined by a radioassay of ${ }^{125} \mathrm{I}$ labeled azidopentanoyl-GGGRGDSGG GY-NH$H_{2}$ model reaction performed in the same condition.

The following groups of materials were prepared:

(1) A non-fouling PDA-PEO layer deposited on a glass coverslip (PEO),

(2) PEO modified with azidopentanoyl-GGGRGDSGG GY-NH ${ }_{2}$, referred to as "RGD",

(3) PEO modified with 24 amino acid-long collagenderived peptide sequence responsible for the collagen-fibronectin interaction (azidopentanoyl-GGG-QRQVVGLO GQRGERGFOGLOG- $\mathrm{NH}_{2}$ ), referred to as "Col", and

(4) PEO modified with a combination of RGD + Col in a ratio of 1:1, i.e., one molecule of RGD per one molecule of Col.

Both peptides were used in two different concentrations, i.e. 90 and $700 \mathrm{fmol} / \mathrm{cm}^{2}$. Surfaces with a combination of RGD + Col contained 90 or $700 \mathrm{fmol} / \mathrm{cm}^{2}$ of each peptide. Unmodified microscopic glass coverslips (the same as used for the film deposition) and standard cell culture polystyrene wells (used for inserting the samples for cell cultivation) were used as reference materials. The glass coverslips were used preferentially for immunofluorescence studies due to their low autofluorescence and possibility to take microphotographs of cells at higher magnifications. As revealed by our preliminary studies, the cell behavior on both glass coverslips and polystyrene wells was similar.

\subsection{Cell seeding conditions}

The materials were sterilized by UV light for $0.5 \mathrm{~h}$ from both sides. The samples were inserted into polystyrene 24-well cell culture plates (TPP, Trasadingen, Switzerland) and were seeded with endothelial cells originating from bovine pulmonary artery (line CPAE ATCC CCL-209, Rockville, MA, USA) in a minimum essential Eagle medium (E-MEM) supplemented with $2 \mathrm{mM}$ L-glutamine, $1.0 \mathrm{mM}$ sodium pyruvate, $0.1 \mathrm{mM}$ non-essential aminoacids and $1.5 \mathrm{~g} / \mathrm{L}$ sodium bicarbonate (all chemicals from Sigma). In order to avoid potential adsorption of serumderived proteins and masking the oligopeptidic ligands, fetal bovine serum (Sebak GmbH, Aidenbach, Germany) was added to the medium $5 \mathrm{~h}$ after cell seeding to a final concentration of $20 \%$ in each well [23]. Each well contained 30,000 cells and $1.5 \mathrm{ml}$ of the medium. The cells were cultured in a humidified atmosphere containing $5 \%$ $\mathrm{CO}_{2}$ in the air.

\subsection{Static cultivation conditions and evaluation of the cell number and morphology}

On day 1, 3 and 7 after seeding, samples were placed in fresh 24-well plates, rinsed with phosphate-buffered saline (PBS; Sigma, USA), and the cells were detached from the materials by a trypsin-EDTA solution (Sigma, USA, Cat. No. T4174), and native unstained cells were counted in a Bürker haemocytometer. Three independent samples were used for each time interval and experimental group.

For evaluation of the shape and distribution of cells on the material surface, the cells were visualized by fluorescent dyes diluted in PBS, namely Hoechst \#33342 (SigmaAldrich, $5 \mu \mathrm{g} / \mathrm{ml}$ ), which stains the cell nuclei, and Texas Red $\mathrm{C}_{2}$-maleimide (Molecular Probes, Invitrogen, Cat. No. $\mathrm{T} 6008,20 \mathrm{ng} / \mathrm{ml}$ ), which stains proteins of the cell membrane and cytoplasm. The cell pictures were taken using an epifluorescence microscope (IX 51, Olympus, Japan) equipped with a digital camera (DP 70, Olympus).

\subsection{Dynamic cultivation conditions and evaluation of the cell number}

The cells were left to adhere for the first $24 \mathrm{~h}$ after seeding under static conditions, and then they were cultivated for 7 days under dynamic conditions using Mini Orbital Shaker SSM1 (Stuart), which provided a uniform circular motion. Thus, the endothelial cells were exposed on their top to a medium flow, which simulated, at least partly, the shear stress in blood vessels in vivo. The speed of the shaker was set to $50 \mathrm{rpm}$ for the next $24 \mathrm{~h}$, and was increased to $80 \mathrm{rpm}$ for the rest of the cultivation period. Finally, the cells were counted in a Bürker haemocytometer. Three independent samples were used for each time interval and experimental group. Cell non-adhesive PEO surfaces were excluded from the evaluation.

The ratios of the cell numbers cultivated under static and dynamic conditions were also evaluated as a parameter 
describing the strength of cell adhesion, i.e. the ability of the adhering cells to withstand the dynamic load.

\subsection{Immunofluorescence staining}

As markers of the formation of focal adhesion plaques on cells, talin and vinculin, i.e., important structural proteins present in focal adhesion plaques and associated with integrin adhesion receptors, were chosen. Talin binds to the intracellular $\beta$-subunit of integrin receptors and associates these receptors with vinculin. Vinculin then controls the focal adhesion formation by its direct interaction with actin cytoskeleton. This interaction leads to clustering of activated integrin receptors into focal adhesion plaques ([24]. Talin and vinculin were stained immunofluorescently on day 3 after seeding, using a procedure described earlier [23, 25]; see also the Supporting Information). Primary monoclonal antibodies (diluted 1:200 in PBS) were Anti-Talin, Clone 8d4 (Cat. No. T3287) and Anti-Vinculin, Clone hVIN-1 (Cat. No. V 9131), both from (Sigma, St. Louis, MO, USA). The secondary antibody was goat anti-mouse $\mathrm{F}(\mathrm{ab}$ ')2 fragment of IgG conjugated with Alexa Fluor 488 (Molecular Probes, Eugene, OR; Cat. No. A11017; dilution 1:1000).

The fluorescence intensity on the microphotographs was measured using Fluorescence Image Analyser software (ver. 1.1, Matejka R., 2013, available from http://alice. fbmi.cvut.cz/software/fia). A single color plane threshold was set on each image to remove the non-protein area from the image data. These threshold and color plane settings were the same for each image of the protein that was measured. Then the cumulative sum of all pixel intensities was evaluated. The total immunofluorescence intensity of the protein was normalized per one cell. The number of analyzed cells was $5-19$ cells for the $90 \mathrm{fmol} / \mathrm{cm}^{2}$ samples, and $17-24$ cells for the $700 \mathrm{fmol} / \mathrm{cm}^{2}$ samples. Cell nonadhesive PEO surfaces were excluded from the evaluation.

The immunofluorescence pictures were also used for evaluating the spreading areas and the circumferences of the cells. The size of the area projected on the material was measured using Atlas software (Tescan Ltd., Brno, Czech Republic). Cells that developed intercellular contacts were excluded from the evaluation.

\subsection{Isolation of mRNA and qPCR}

The cells were harvested after 3-day cultivation on the tested samples under static conditions. Total RNA was isolated using the Total RNA Purification Micro Kit (Norgen Biotek). The cells growing on the surfaces carrying oligopeptides were transferred in a fresh plate, rinsed with phosphate-buffered saline (PBS; Sigma, USA) and extracted from the material surface using the lysis solution enriched with $1 \%$ mercaptoethanol. Five samples were pooled for the mRNA isolation. Reverse transcription was performed using Omniscript Reverse Transcription Kit (Qiagen).

The mRNA levels were quantified by quantitative realtime 5xHOT FIREPol Probe qPCR Mix Plus (ROX) (Solis BioDyne) and with TaqMan Gene Expression Assays (Life Technologies) labelled with FAM reporter dye specific to bovine TAL1 (Cat. No. Bt04291881_m1), VCL (Cat. No. Bt04306059_ m1) and FN1 (Cat. No. Bt00415008_m1). The experiments were performed in duplicates with ACTB (Cat. No. Bt03279174_m1, reporter dye VIC) as a reference gene, in a final reaction volume of $20 \mu \mathrm{l}$ per well on a 96-well optical reaction plate using the Viia ${ }^{\mathrm{TM}} 7$ Real-time PCR System.

Data are the mean of 4-5 experimental points from 2 independent experiments. Expression values were obtained from $C_{t}$ numbers. The target gene levels are expressed as a relative value, the ratio of the target gene expression towards the reference ACTB gene. The relative gene expression was calculated as $2^{-\Delta \mathrm{Ct}}$.

\subsection{Statistical analysis}

The quantitative data was presented as mean \pm standard error of mean (SEM). Statistical analyses were performed using SigmaStat (Jandel Corp., USA). Multiple comparison procedures were made by the one way analysis of variance (ANOVA), Student-Newman-Keuls method. $P$ values equal to or less than 0.05 were considered significant.

\section{Results}

\subsection{Fibronectin adsorption to the newly developed surfaces}

The short-term interaction between fibronectin (FN) and the pristine PDA-PEO and their counterparts bearing different peptide motifs were followed by SPR [26]. The pristine PDA-PEO layers proved to form an excellent barrier that almost completely cancels the nonspecific interactions between FN and the surface (Fig. 1). The FN deposits on these surfaces reached values of only $2 \mathrm{ng} / \mathrm{cm}^{2}$, which corresponds to a $98 \%$ reduction compared to the deposits adsorbed on bare gold $\left(97 \pm 5 \mathrm{ng} / \mathrm{cm}^{2}\right)$. Statistically significant $(P<0.05)$ deposits of $\mathrm{FN}$ on the majority of peptide bearing PEO-PDA layers were measured in comparison to the pristine PDA-PEO. Specifically, the adsorption of FN was significantly higher on surfaces with $700 \mathrm{fmol} / \mathrm{cm}^{2}$ of RGD, 90 and $700 \mathrm{fmol} / \mathrm{cm}^{2}$ of $\mathrm{Col}$, and with $90 \mathrm{fmol} / \mathrm{cm}^{2}$ RGD + Col than on PDA-PEO, although this adsorption was significantly lower than on 


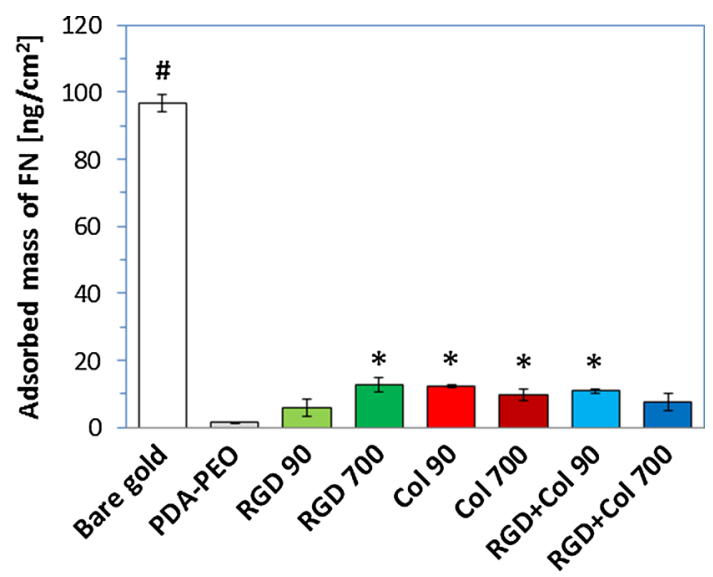

Fig. 1 The adsorption of fibronectin (FN) on pristine PDA-PEO surfaces and these surfaces functionalized with RGD a collagen derived peptide $(\mathrm{Col})$ or a combination of RGD + Col in concentrations of 90 or $700 \mathrm{fmol} / \mathrm{cm}^{2}$ for each peptide, as determined by SPR. FN adsorption on bare gold is reported as a reference. Mean \pm SEM from 3 to 6 independent measurements. ANOVA Student-NewmanKeuls method. Statistical significance $(P<0.05)$ : " higher than all other groups, *higher than the PEO-PDA group

bare gold. Thus, the immobilization of the RGD, Col and RGD + Col peptide sequences decreased the initially observed non-fouling properties of the layers. The FN deposits on the peptide-bearing surfaces reached values of about $10 \mathrm{ng} / \mathrm{cm}^{2}$ (a reduction of $90 \%$ in comparison with bare gold), irrespective of the peptide surface concentration, i.e. 90 or $700 \mathrm{fmol} / \mathrm{cm}^{2}$ (Fig. 1).

\subsection{Number of endothelial cells on the tested materials}

On day 1 after seeding, the numbers of initially adhered cells on pristine PEO-PDA surfaces, and also on all surfaces modified with oligopeptides at the concentration of $90 \mathrm{fmol} / \mathrm{cm}^{2}$, were significantly lower than on the standard cell culture polystyrene dishes (Fig. 2a). Only the cell numbers on surfaces with RGD or Col were significantly higher than the cell numbers on PEO-PDA. However, on surfaces functionalized with oligopeptides in the concentration of $700 \mathrm{fmol} / \mathrm{cm}^{2}$, the cells reached significantly higher numbers than on PEO-PDA, and these numbers approached the value on the control polystyrene (Fig. 2b). Similar cell behavior on the tested surfaces was also observed on day 3 after seeding (Fig. 3a, c). On day 7 after seeding, the cell numbers were higher on the peptidebearing surfaces than on the pristine PEO-PDA surfaces, but these numbers still remained lower than on the control polystyrene dishes. However, from day 3 to 7 , the cells on the RGD + Col surfaces with both peptide concentrations proliferated more quickly than the cells on the RGD surfaces, as indicated by the steeper rise of the growth curves (Fig. 3b, d). As a result, the cells on surfaces with
RGD + Col concentration attained a similar or a slightly higher number in comparison with the other peptidemodified surfaces.

\subsection{Ratio of the cell numbers under dynamic and static cultivation}

Interesting results were obtained when the cells were cultivated under dynamic conditions using the Mini Orbital Shaker SSM1. In this system the medium flows over the endothelial cells, exerting a shear stress on them. On day 7 after seeding, the ratio between the cell numbers in the dynamic and conventional static culture systems was calculated. This number can be considered as a measure of the resistance of the cells to detachment by the dynamic load. At a lower peptide concentration, this resistance was similar on all tested samples, i.e. on microscopic glass coverslips, on polystyrene dishes, and on samples functionalized with RGD, Col or RGD + Col. However, at a higher peptide concentration, the resistance was remarkably higher on the RGD + Col surfaces than on the other samples (Fig. 4). Thus, RGD-functionalization seems to be important for initial cell adhesion, but combined RGD + Col functionalization is necessary for further growth and retention of the cells, particularly under a dynamic load.

\subsection{Morphology and spreading of endothelial cells cultured on the tested materials}

On the PEO-PDA layer, the cells were very sparse and round, and if they were spread, it seemed that they were located in defects of the PEO films, such as scratches caused by handling the samples (Fig. 5). On the other hand, the cells on the peptide-functionalized surfaces were more numerous, well-spread and mostly polygonal, although the number and spreading of cells on samples with the lower concentration of $\mathrm{Col}$ and RGD + Col were lower than on polystyrene and glass coverslips (Figs. 5, 6a). On samples with a higher concentration of $\mathrm{Col}$ and $\mathrm{RGD}+\mathrm{Col}$, the cell spreading area on day 3 after seeding was similar to that on control glass coverslips (Fig. 6b), and on day 7 (Fig. 6), the cells on these samples formed fully confluent layers similarly as on polystyrene (Fig. 5). Only on surfaces with RGD, the cell spreading area was significantly smaller than on glass (Fig. 6b), and on day 7, these cells were subconfluent (Fig. 5).

\subsection{Immunofluorescence of talin and vinculin in cells on the tested materials}

Talin- or vinculin-containing focal adhesion plaque were more numerous and better-developed in cells on surfaces 


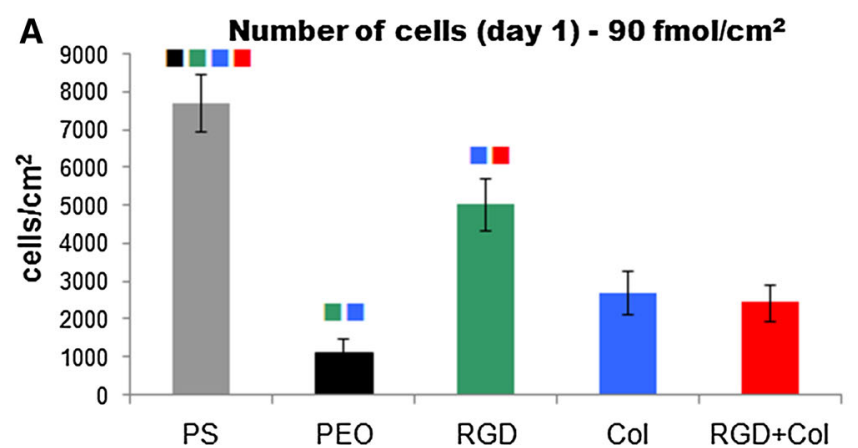

Fig. 2 The number of endothelial CPAE cells initially adhering on standard cell culture polystyrene dishes (PS), on non-fouling PDAPEO surfaces (PEO), and on PEO surfaces functionalized with RGD (RGD), a collagen derived peptide (Col) or a combination of $\mathrm{RGD}+\mathrm{Col}$ in concentrations of $90 \mathrm{fmol} / \mathrm{cm}^{2}$ (a) or $700 \mathrm{fmol} / \mathrm{cm}^{2}$
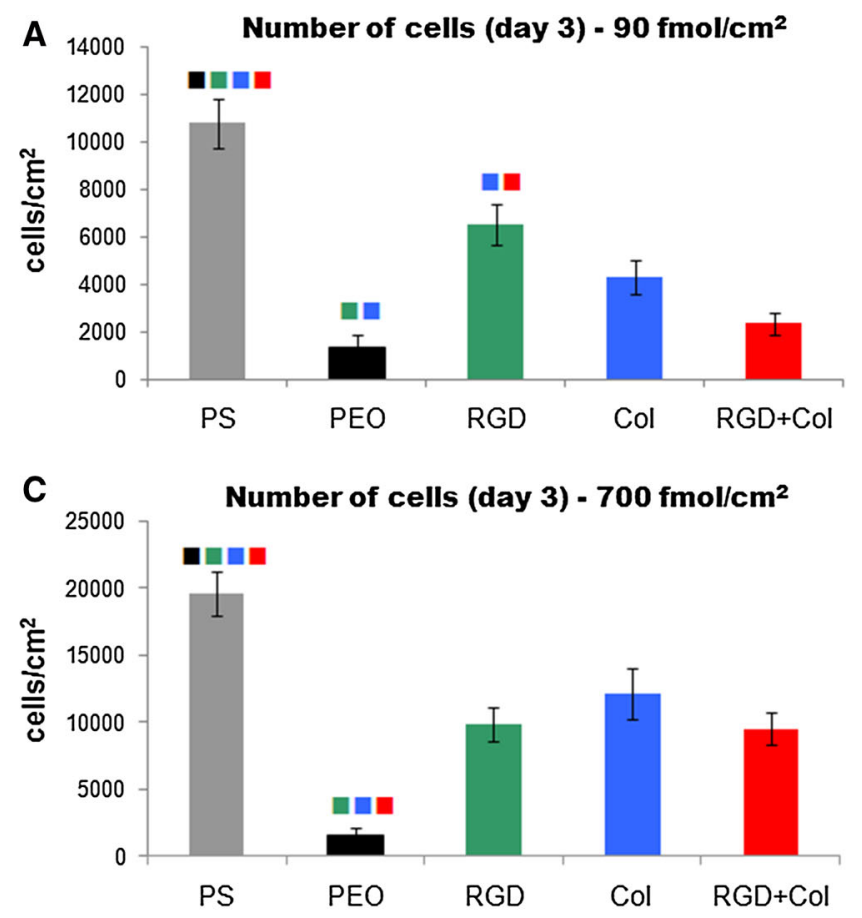

Fig. 3 a and $\mathbf{c}$ The number of endothelial CPAE cells on day 3 after seeding on standard cell culture polystyrene dishes (PS), on nonfouling PDA-PEO surfaces (PEO), and on PEO surfaces functionalized with RGD (RGD), a collagen-derived peptide (Col), or a combination of RGD + Col in concentrations of 90 or $700 \mathrm{fmol} / \mathrm{cm}^{2}$ for each peptide. $\mathbf{b}$ and $\mathbf{d}$ Growth dynamics of endothelial cells during

with a higher peptide concentration and on the control microscopic glass coverslips than in the cells on surfaces with a lower peptide concentration, where talin and vinculin were distributed rather diffusely (Fig. 7). Similarly, the intensity of the fluorescence of talin and vinculin in the cells on surfaces with a lower peptide concentration was generally lower than in the cells on the glass coverslips (Fig. 8a, b). On the samples with a higher peptide

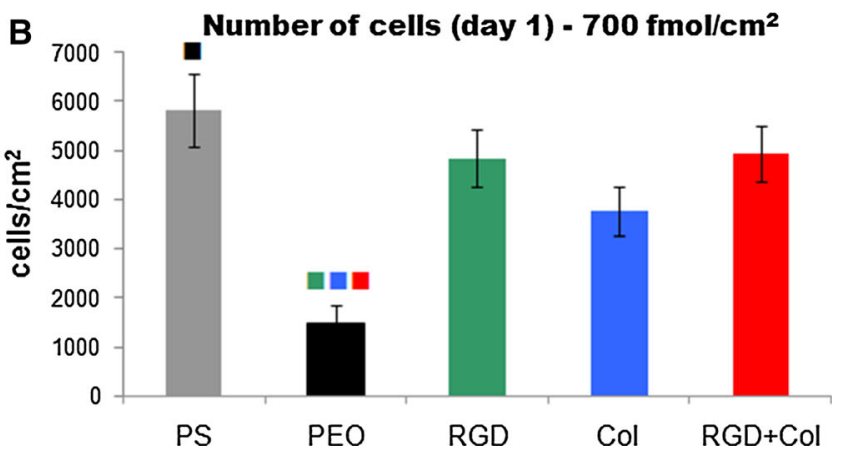

(b) for each peptide. Mean \pm SEM from three samples for each experimental group and time interval. ANOVA Student-NewmanKeuls method. Statistical significance $(P<0.05)$ in comparison with other experimental groups is indicated by the colors of these groups above the columns (Color figure online)
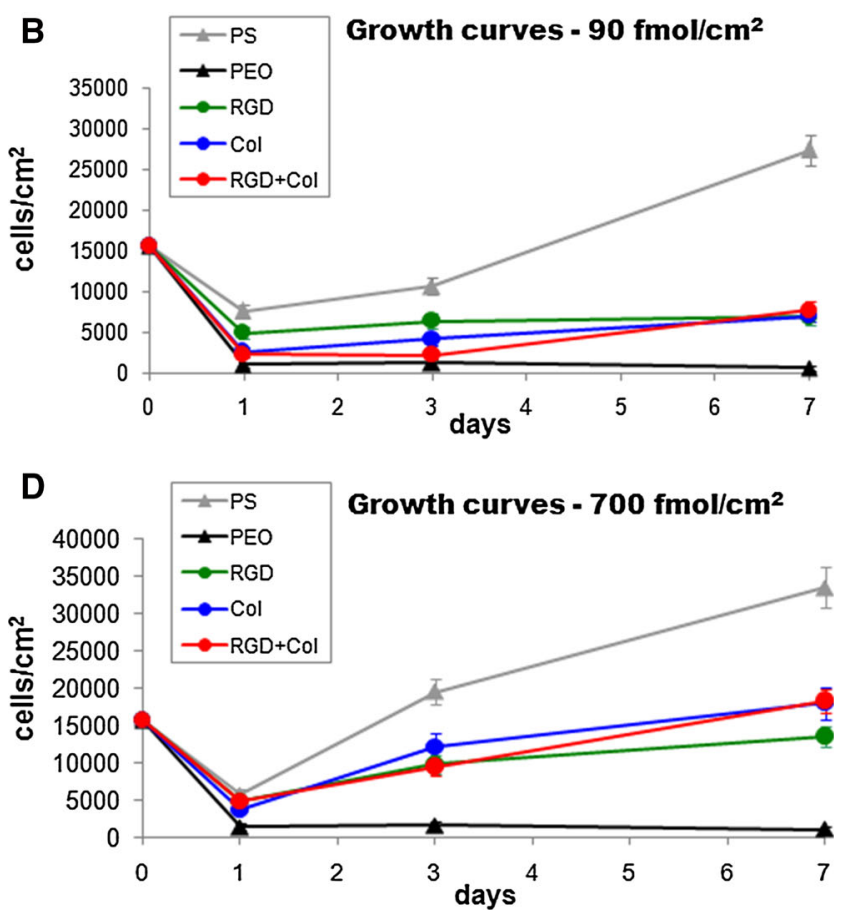

1 week of cultivation on the same materials. Mean \pm SEM from three samples for each experimental group and time interval. ANOVA, Student-Newman-Keuls method. Statistical significance $(P<0.05)$ in comparison with other experimental groups is indicated by the colors of the groups above the columns. d Col, RGD + Col: $P<0.05$ compared to RGD on day 7 (Color figure online)

concentration, the intensity of the fluorescence of talin and vinculin was usually similar to the value detected in the cells on the glass coverslips (Fig. 8c, d). Moreover, in the cells on samples with a Col concentration of $700 \mathrm{fmol} / \mathrm{cm}^{2}$, the intensity of the fluorescence of talin was even higher than on the glass coverslips and on surfaces with the corresponding concentrations of RGD and RGD + Col (Fig. 8c). 


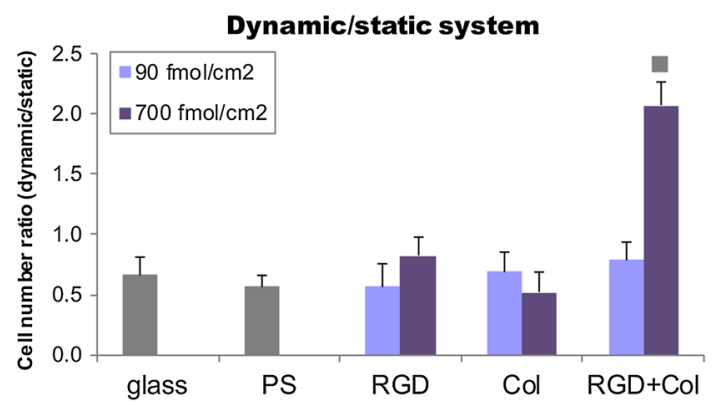

Fig. 4 The ratio of cell numbers obtained in dynamic and static cell culture systems on day 7 after seeding on microscopic glass coverslips (glass), on standard cell culture polystyrene dishes (PS), and on PEO surfaces functionalized with RGD (RGD), with a collagen-derived peptide $(\mathrm{Col})$ or with a combination of RGD $+\mathrm{Col}$ in concentrations of $90 \mathrm{fmol} / \mathrm{cm}^{2}$ (light blue columns) or $700 \mathrm{fmol} /$ $\mathrm{cm}^{2}$ (dark blue columns) for each peptide. Mean \pm SEM from 53 samples for each experimental group. ANOVA, Student-NewmanKeuls method. Statistical significance: $\boldsymbol{\nabla}_{P}<0.05$ compared with all other samples (Color figure online)

\subsection{Expression of genes for talin, vinculin and fibronectin in cells on the tested surfaces}

We found that the expression of talin in cells growing on the surfaces bearing all peptides in both concentrations was significantly higher than in the cells on the control glass coverslips and on polystyrene dishes. The maximum talin expression was achieved in cells growing on surfaces with $\mathrm{RGD}+\mathrm{Col}$ in a concentration of $700 \mathrm{fmol} / \mathrm{cm}^{2}$ (Fig. 9a). The relative mRNA expression of talin in the cells on this sample reached $268 \%$ of the value obtained on the control glass coverslips. This result was in good correlation with the highest resistance of cells on these samples to the dynamic load (cf. Fig. 4). In addition, the expression of vinculin was significantly higher in the cells on surfaces with RGD + Col in a higher concentration than on the glass coverslips and polystyrene dishes, while in the cells on samples with RGD or Col only, the vinculin expression was similar as in the cells on both control substrates (Fig. 9b). Surprisingly, there was the highest expression of fibronectin in the cells grown on surfaces functionalized with RGD $\left(700 \mathrm{fmol} / \mathrm{cm}^{2}\right)$, though this had been anticipated on surfaces containing the fibronectin-binding collagen-derived peptide (Col, $\mathrm{RGD}+\mathrm{Col})$.

\section{Discussion}

Protein-repulsive surfaces have been widely used for modulating cell adhesion and proliferation. The non-fouling properties of these surfaces have been exploited for constructing biochips [27], for antimicrobial coatings [28], for inhibiting platelet adhesion and hemocoagulation on blood-contacting devices [29], for functionalization with growth and differentiation factors $[12,30,31]$ and particularly as a cell non-adhesive bioinert background for the attachment of adhesion oligopeptides in defined concentrations, spacing and distribution in order to control the adhesion, spreading, growth and differentiation of cells $[19,23,25,32]$. Our recent work investigated the level of protein absorption on an RGD-modified PDA-PEO surface (unpublished results). The amino acid sequence RGD is typically contained in fibronectin and vitronectin, and is recognized by integrin adhesion receptors on many cell types. The novelty of this study lies in the modification of the material surface not only with RGD as a ligand for cell adhesion receptors, but also with ligands allowing a specific interaction with fibronectin in order to facilitate the deposition of ECM on the scaffolds. We hypothesized that immobilizing the collagen fragment responsible for collagen-fibronectin interaction allows cell-expressed fibronectin to be specifically anchored to the protein-repulsive surface. The collagen I-derived peptide QRQVVGLOGQR GERGFOGLOG-NH${ }_{2}$ was chosen for these purposes [18].

The peptide concentration level on the material surface was adjusted according to the following assumption. On the one hand, the maximal peptide surface concentration should be at a level where the only peptide ligand can interact with the only integrin receptor. Adopting the published diameter of the integrin head of 7-10 nm [33], we deduced that the ligand surface concentration must be below $2000 \mathrm{fmol} / \mathrm{cm}^{2}$.

On the other hand, the minimal peptide concentration for integrin-mediated cell adhesion has been observed at a level of $10 \mathrm{fmol} / \mathrm{cm}^{2}$ [34], and the optimal RGD spacing distance for fibroblast focal adhesion formation has been observed at a level of $58 \mathrm{~nm}$, which represents a peptide surface concentration of $57 \mathrm{fmol} / \mathrm{cm}^{2}$ [35].

We therefore decided to use a peptide ligand concentration at levels of 1000 and $100 \mathrm{fmol} / \mathrm{cm}^{2}$. For $12.7 \mathrm{~nm}$ in thickness, the concentration of the alkyne group suitable for peptide modification is at a level of $2.76 \times 10^{-10} \mathrm{~mol} / \mathrm{cm}^{2}$. To achieve the designed peptide surface concentration, the sample modification was therefore driven using diluted peptide solutions according to our earlier study [19].

The real level of 90 and $700 \mathrm{fmol} / \mathrm{cm}^{2}$ of the ligand surface concentration was finally determined by a radioassay of the ${ }^{125}$ I labeled peptide, which corresponds to ligand spacing of 46 and $14 \mathrm{~nm}$, respectively. For surfaces modified by a combination of RGD + Col, containing 90 and $700 \mathrm{fmol} /$ $\mathrm{cm}^{2}$ for each peptide, i.e. 180 and $1400 \mathrm{fmol} / \mathrm{cm}^{2}$ in total, the ligand spacing was shorter, i.e. 33 and $10 \mathrm{~nm}$, respectively.

The first finding of this study confirmed the cell nonadhesive effect of the protein-repulsive PEO layer. As is generally known, this effect is due to the high hydrophilicity of this layer, associated with the mobility of 


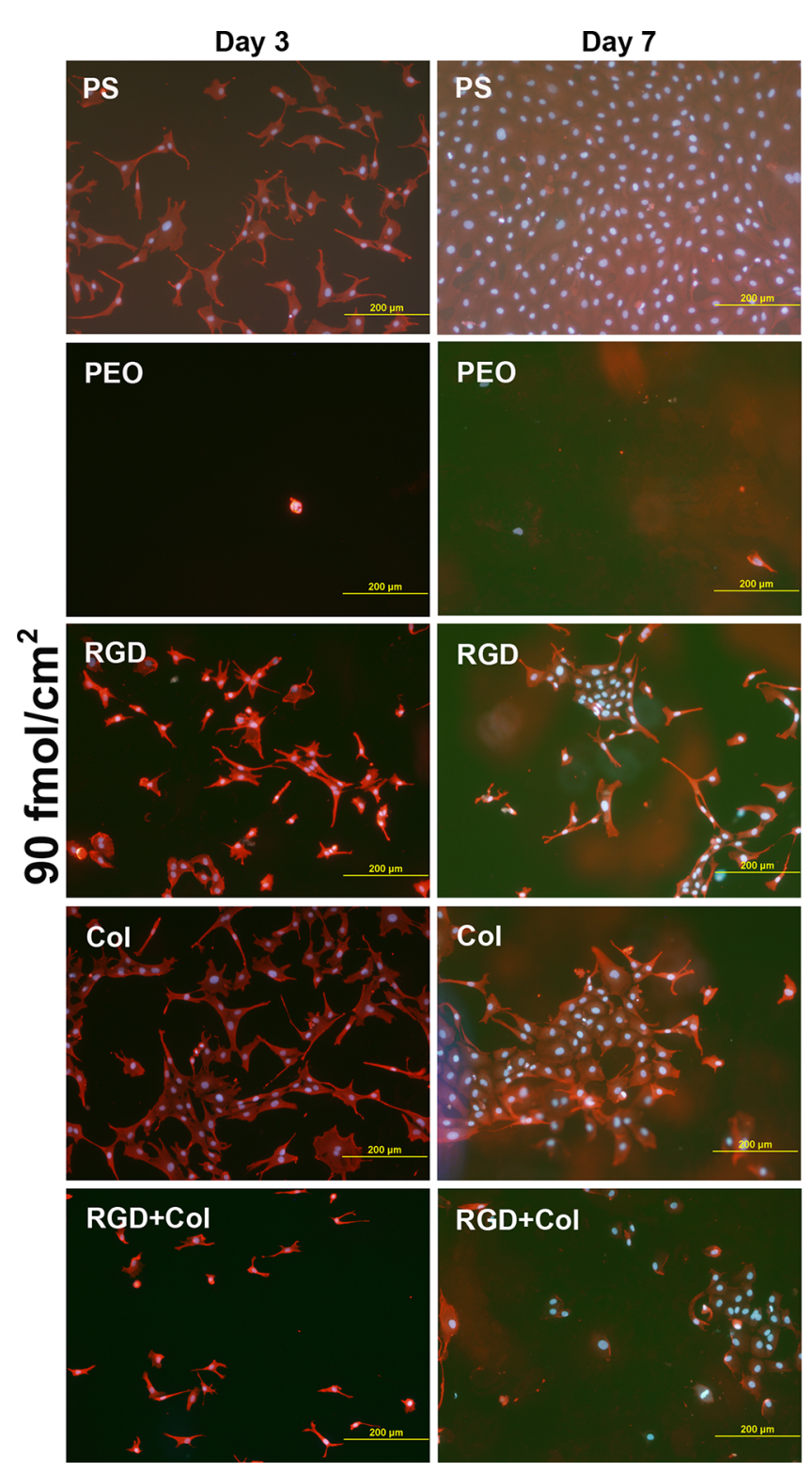

Fig. 5 Morphology of endothelial CPAE cells on days 3 and 7 after seeding on standard cell culture polystyrene dishes (PS), on nonfouling PDA-PEO surfaces (PEO), and on PEO surfaces functionalized with RGD (RGD), with collagen-derived peptide (Col) or with a

the densely packed PEO chains, which hinders protein adsorption and successive cell adhesion. Similar results were also obtained in our earlier study performed on rat aortic smooth muscle cells cultured on PDLLA-PEO copolymers with $33 \%$ of PEO [25]. Even on peptidefunctionalized surfaces, the adsorption of fibronectin was very low, and was similar in all peptide-bearing surfaces. Surfaces exhibiting such low fouling from fibronectin can be expected to elicit different peptide sequences, so it was possible to establish the specific cell/RGD-ligand and cell/ $\mathrm{FN} / \mathrm{Col}$ in the cell seeding studies.

When the PEO surfaces were functionalized with higher concentrations of RGD, with a collagen-derived peptide
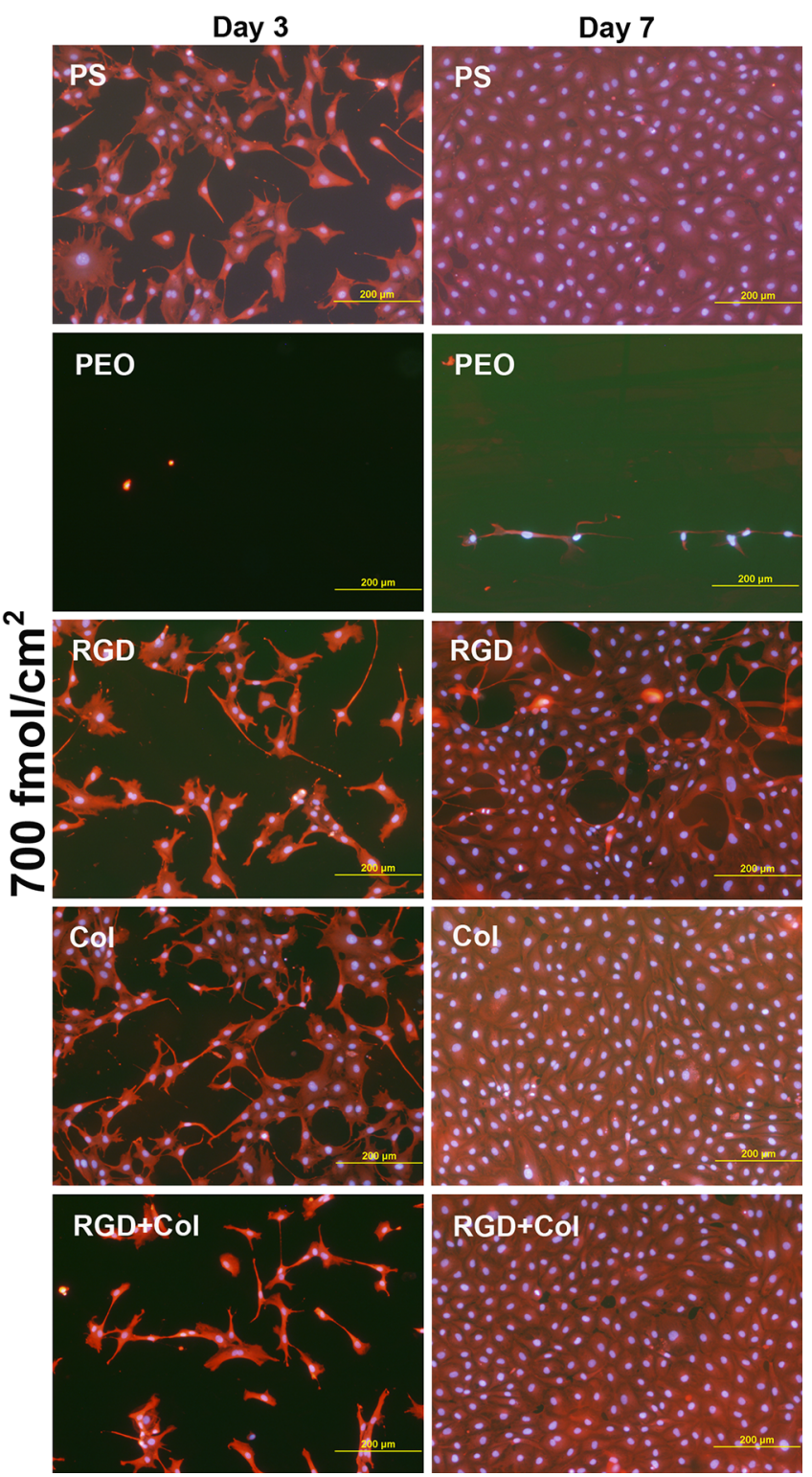

combination of RGD + Col at concentrations of 90 or $700 \mathrm{fmol} / \mathrm{cm}^{2}$ for each peptide. Cells stained with Texas Red $\mathrm{C}_{2}$-Maleimide and Hoechst \#33342. Olympus IX 51 microscope, obj. $\times 20$, DP 70 digital camera, bar $200 \mu \mathrm{m}$

(Col), or with a combination of RGD + Col, cell adhesion and growth were almost completely restored, i.e. became similar as on standard cell culture polystyrene dishes or on control microscopic glass coverslips. However, on surfaces with a low peptide concentration, the cell colonization was noticeably improved practically only on the RGD-functionalized surface. The cell numbers on the RGD $+\mathrm{Col}$ surface even did not significantly exceed the values on the PEO surface, and the spreading of cells on RGD + Col and Col surfaces was significantly lower than on RGD-bearing surfaces. These results were surprising, because the ligand spacing on the Col and RGD + Col samples with a lower ligand concentration was calculated to be 46 and $33 \mathrm{~nm}$, 


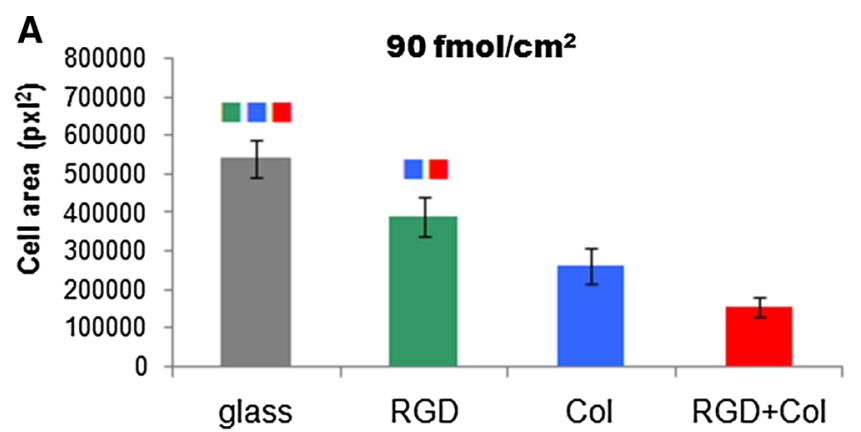

Fig. 6 The size of the spreading areas of the endothelial CPAE cells on day 3 after seeding on the control microscopic glass coverslips (glass), PEO surfaces functionalized with RGD, with collagenderived peptide $(\mathrm{Col})$ or with a combination of $\mathrm{RGD}+\mathrm{Col}$ in a concentration of $90 \mathrm{fmol} / \mathrm{cm}^{2}$ (a) or $700 \mathrm{fmol} / \mathrm{cm}^{2}$ (b) for each peptide. Measured on pictures of cells with immunofluorescence
B

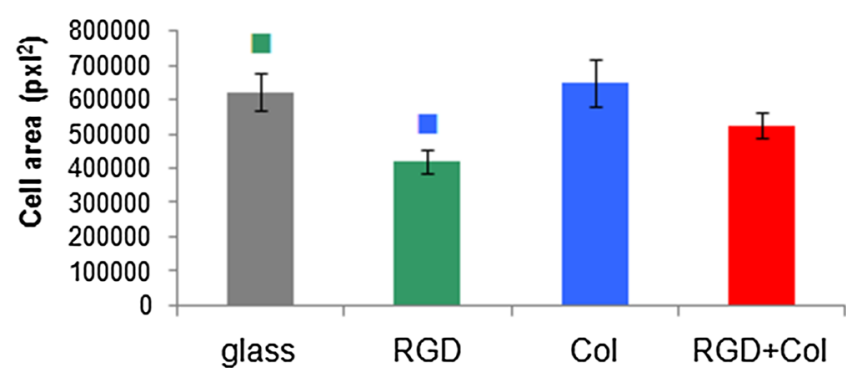

staining of talin and vinculin. Mean \pm SEM from 5 to 19 measured cells for the $90 \mathrm{fmol} / \mathrm{cm}^{2}$ samples, and 17-24 cells for the $700 \mathrm{fmol} /$ $\mathrm{cm}^{2}$ samples. ANOVA, Student-Newman-Keuls method. Statistical significance $(P<0.05)$ in comparison with other experimental groups is indicated by the colors of the groups above the columns (Color figure online)
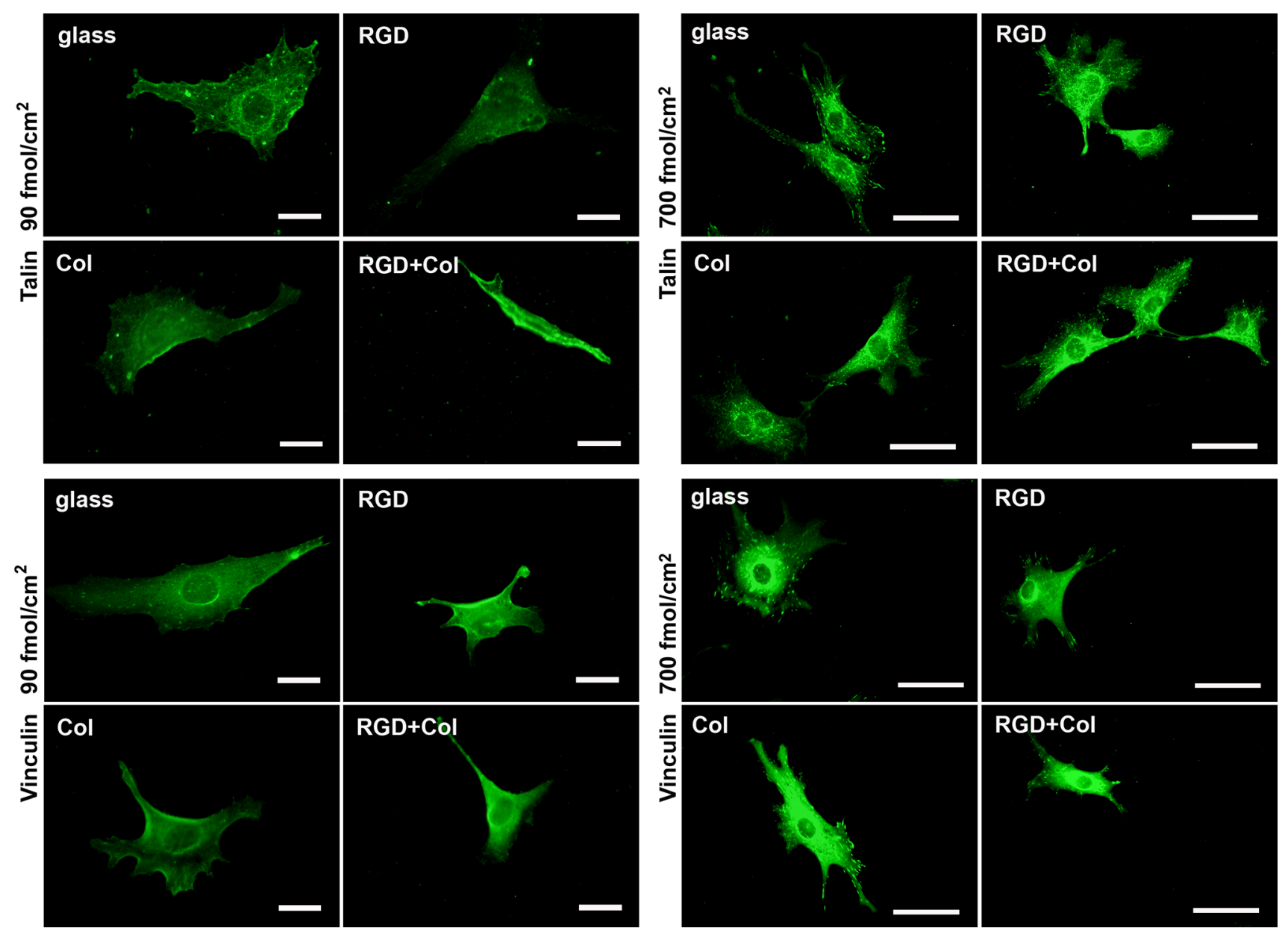

Fig. 7 Immunofluorescence staining of talin and vinculin in endothelial CPAE cells on day 3 after seeding on the control microscopic glass coverslips (glass), and on PEO surfaces functionalized with $\mathrm{RGD}$, with a collagen-derived peptide (Col) or with a combination of

RGD + Col in concentrations of 90 or $700 \mathrm{fmol} / \mathrm{cm}^{2}$. Magnification, bar, exposure time: $90 \mathrm{fmol} / \mathrm{cm}^{2}$ samples: $\times 64,20 \mu \mathrm{m}$, talin: $1800 \mathrm{~ms}$, vinculin: $1400 \mathrm{~ms} ; 700 \mathrm{fmol} / \mathrm{cm}^{2}$ samples: $\times 40,50 \mu \mathrm{m}$, talin: $909 \mathrm{~ms}$, vinculin: $625 \mathrm{~ms}$, respectively 

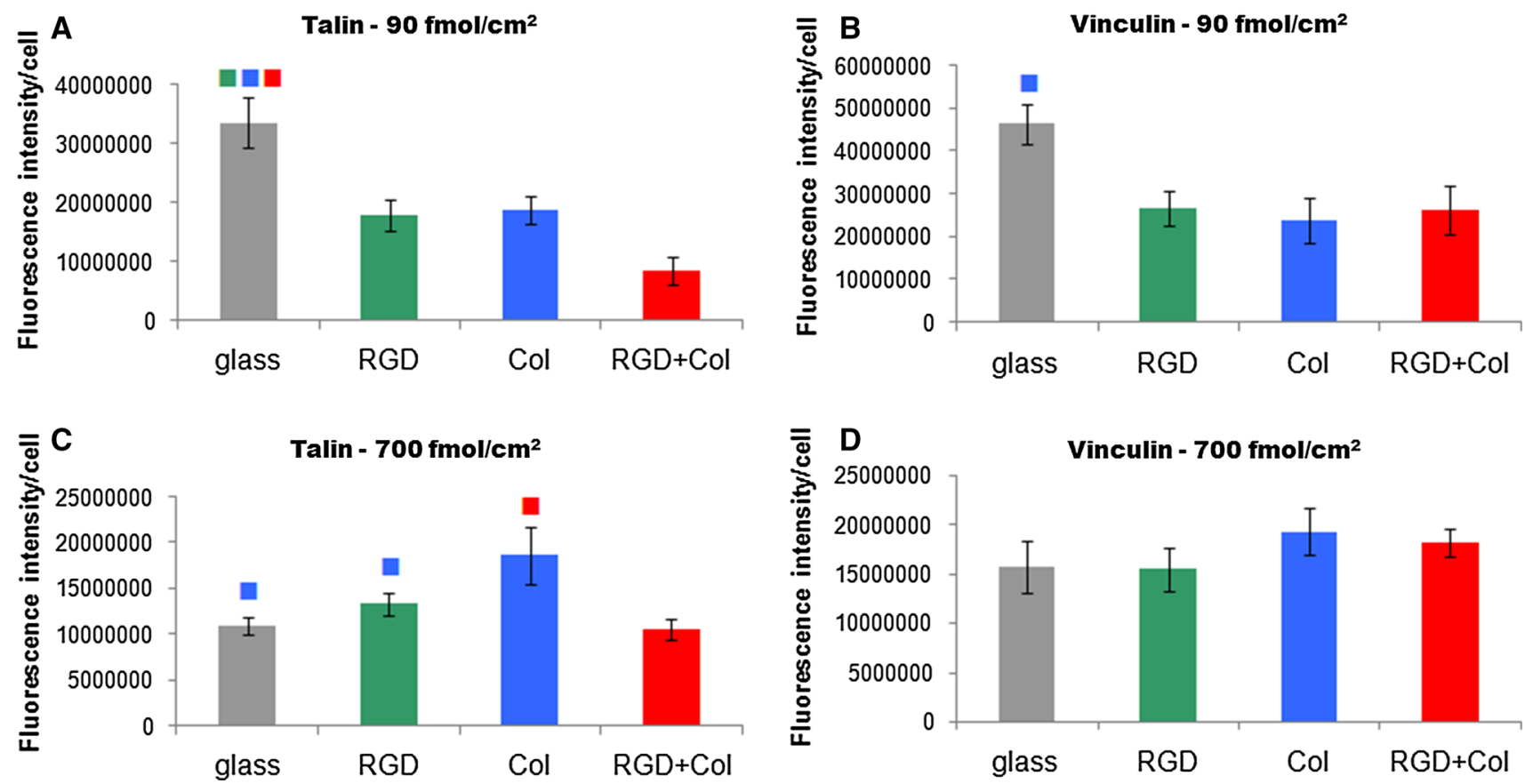

Fig. 8 Intensity of the immunofluorescence of talin $(\mathbf{a}, \mathbf{c})$ and vinculin (b, d) in endothelial CPAE cells on day 3 after seeding on the control microscopic glass coverslips (glass), on PEO surfaces functionalized with RGD (RGD), with a collagen-derived peptide (Col) or with a combination of RGD $+\mathrm{Col}$ in concentrations of $90 \mathrm{fmol} / \mathrm{cm}^{2}\left(\mathbf{a}\right.$, b) or $700 \mathrm{fmol} / \mathrm{cm}^{2}$ (c, d) for each peptide. The

which is below the limit of $70 \mathrm{~nm}$ ligand spacing described for the spreading and growth of mouse osteoprogenitor MC3T3-E1 cells and rat bone marrow mesenchymal stem cells $[36,37]$.

An explanation for this cell behavior could therefore lie in differences in binding the RGD and Col oligopeptides by cell adhesion receptors. The RGD sequence, present in vitronectin, fibronectin, fibrinogen, thrombospondin, osteopontin or in the von Willebrand factor, is recognized by the integrin receptors with an $\alpha_{v}$ chain, e.g. $\alpha_{v} \beta_{3}$ integrin [38]. These receptors are known to be associated with migration and proliferation of cells, e.g. during developmental and regeneration processes, and also during tumorigenesis [39] or vascular diseases [40]. It can be speculated that, in our system, these receptors were expressed preferentially on cells in early culture intervals (days 1-3 after seeding), when the cells were actively migrating and proliferating, while the receptors for collagen, i.e. integrins with a $\beta_{1}$ chain $\left(\alpha_{1} \beta_{1}, \alpha_{2} \beta_{1}\right.$ and $\left.\alpha_{3} \beta_{1}\right)$, associated rather with a more mature state of the cells [41, 42], occurred at later culture intervals (days 3-7). In accordance with this assumption, from day 3 to day 7 there was an improvement in cell performance on surfaces with lower concentrations of $\mathrm{Col}$ or RGD + Col. Although the intensity of the fluorescence of talin and vinculin still remained low in the cells on these surfaces, the expression

magnification and exposure time of pictures used for the measurement is described in Fig. 7. Mean \pm SEM from 5 to 19 cells for $90 \mathrm{fmol} /$ $\mathrm{cm}^{2}$ samples, and $17-24$ cells for $700 \mathrm{fmol} / \mathrm{cm}^{2}$ samples. ANOVA, Student-Newman-Keuls method. Statistical significance $(P<0.05)$ in comparison with other experimental groups is indicated by the colors of the groups above the columns (Color figure online)

of mRNA for these proteins was similar to (vinculin) or even higher than (talin) in the cells on the control polystyrene surfaces. The cytoskeletal adaptor protein talin has been proposed to play an important role in regulating integrin affinity. Binding the talin head region to the integrin $\beta$ cytoplasmic tail causes dissociation of the $\alpha$ and $\beta$ tails, and induces a conformational change in the extracellular region that increases the affinity of an integrin receptor for its ligand [43].

Another interesting finding was that on surfaces with a lower peptide concentration the cell numbers, the spreading and the intensity of the fluorescence of talin tended to be lower on surfaces with RGD + Col than on surfaces with Col only. On samples with a higher peptide concentration, the intensity of the fluorescence of talin in the cells on RGD + Col surfaces was significantly lower than on Col surfaces. In other words, the cell adhesion was attenuated when both RGD + Col ligands were present on the material surface. Similar cell behavior was observed on combined fibronectin/collagen matrices, where the spreading and the proliferation of rat aortic smooth muscle cells was lower than on the pure fibronectin or on the pure collagen [44]. On the combined matrices, both fibronectin and collagen were recognized by the same receptor, which was probably able to receive and process the signals from both proteins simultaneously. However, a weaker cell 

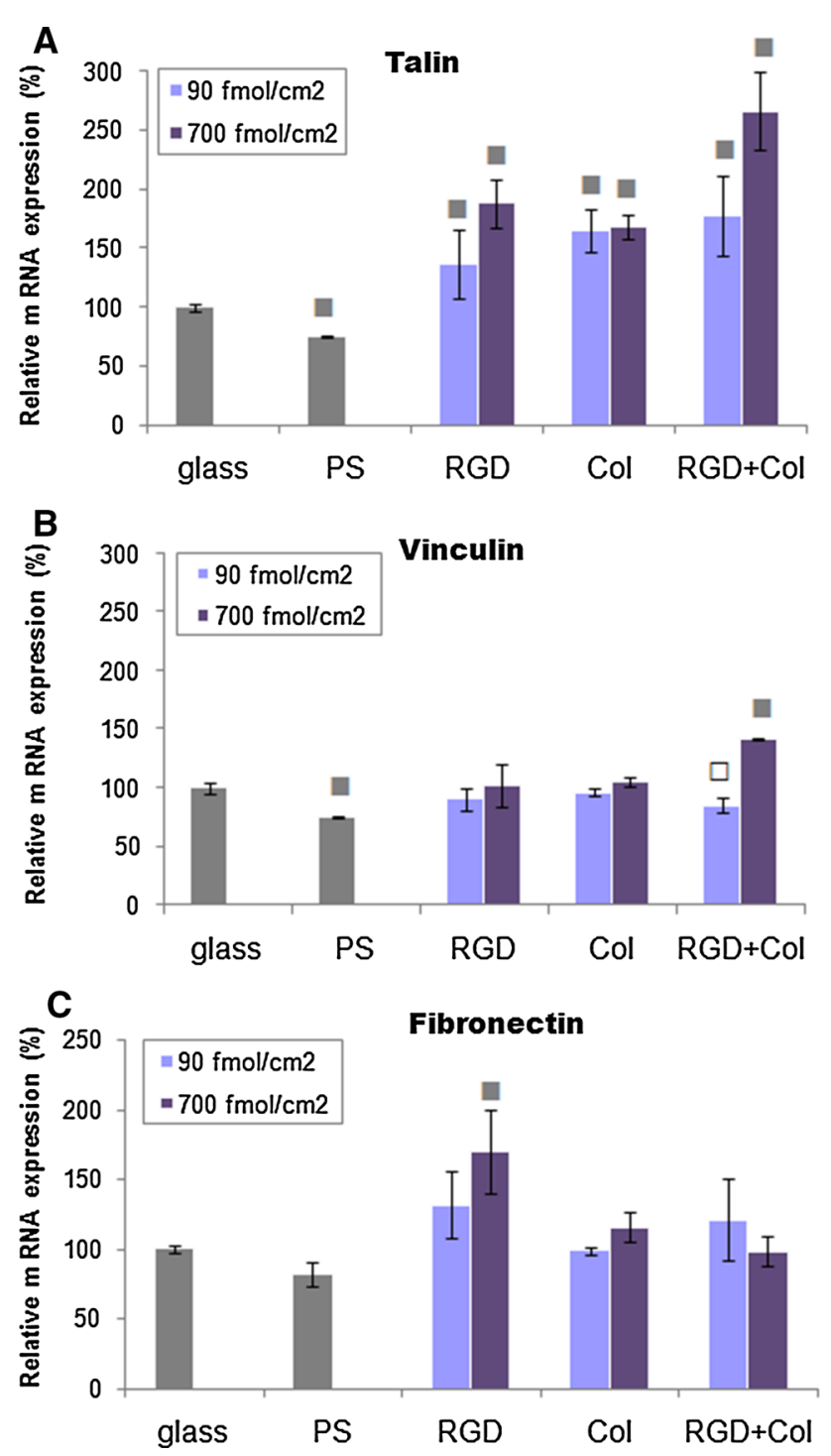

Fig. 9 Relative expression of genes for focal adhesion proteins talin (a), vinculin (b) and for an ECM protein fibronectin (c) in endothelial CPAE cells on day 3 after seeding on the control microscopic glass coverslips (glass), on standard polystyrene cell culture dishes (PS), and on PDA-PEO surfaces functionalized with RGD (RGD), with a collagen-derived peptide ( $\mathrm{Col})$ or with a combination of RGD + Col peptides in concentrations of 90 or $700 \mathrm{fmol} / \mathrm{cm}^{2}$ for each peptide. The data are expressed as values relative to the gene expression in cells grown on microscopic glass coverslips $(100 \%)$. Mean \pm SD. (Standard deviation) from 5 to 6 experimental points from three independent experiments. ANOVA, Student-Newman-Keuls method. Statistical significance: $\boldsymbol{\square}_{P}<0.001,{ }^{\square} P<0.02$ compared to the values on glass

response to this combined signal suggested steric problems of simultaneous integrin binding to both collagen and fibronectin binding sites [44]. Similar steric problems may also have occurred on our surfaces functionalized by a combination of RGD + Col.

Another possibility is that RGD and Col ligands did not both bind to the same receptor simultaneously, but that they competed for this receptor. Competition between two or more ligands for one type of integrin receptor is possible. Although a certain type of integrin receptor preferentially binds a certain ligand, this interaction is not strongly specific, and the receptor can also bind an alternative ligand [38]; for a review, see Bacakova et al. [2] This is because integrin-ligand binding depends mainly on the spatial conformation of both receptor and ligand, which is relatively flexible and changeable. For example, the receptors for RGD could also bind similar sequences, e.g. RGE, i.e. a sequence present in the Col peptide used in our study, which is shorter than RGD only by one carbon. However, similarly as in the case of combined binding of two ligands, the binding of an alternative ligand could be weaker and less bioactive, i.e. not able to initiate an adequate biochemical cascade and cell response. For example, a recombinant lipoprotein $\mathrm{T}$ in which RGD was mutated to RGE retained only $45 \%$ of the binding activity for LSM 192 primary lamb joint synovial cells in comparison with lipoprotein $\mathrm{T}$ with intact RGD [45].

Nevertheless, the weaker response of the cells to combined RGD + Col signaling was markedly improved for samples with a higher peptide concentration. It was probably compensated by high ligand concentration and very short ligand spacing $(10 \mathrm{~nm})$, which was similar to the size of the head of the integrin receptor [33]. It can therefore be considered as the minimum ligand spacing. From day 3 to day 7 , the cells on RGD + Col proliferated more quickly than the cells on pure RGD or on pure Col, and on day 7 they reached confluence, while on pure RGD, the cells were only semiconfluent. The expression of mRNA for talin and vinculin was highest on the RGD + Col surfaces, which was in good correlation with the highest stability of the cell adhesion on these surfaces under a dynamic load.

The highest expression of fibronectin was obtained in cells on the surface modified with RGD at the higher concentration. Similarly, on PEG hydrogels functionalized with RGD in combination with PHSRN, the production of ECM in osteoblasts was lower than in cells on surfaces bearing RGD only [46]. The explanation was that the combination of RGD + PHSRN, which mimicked ECM more closely than RGD alone, downregulated the ECM production. Similarly, the relatively long collagen peptide used in our study and its combination with RGD was able to mimic ECM more closely than RGD alone. The collagen peptide is known to bind fibronectin, which may further enhance its similarity with the native ECM. However, in our study, SPR revealed that the adsorption of fibronectin on the surfaces bearing Col and RGD + Col in both concentrations was similar as on all peptide-modified surfaces. The expected specific interactions between FN and surfaces bearing the Col peptide sequence could not be uniquely proved on the basis of the short-term SPR 
experiment. We hypothesize that this may be caused by the steric hindrance of the surface-bound Col peptide not allowing effective interaction with the fibronectin molecule. This is an issue that needs further investigation.

\section{Conclusion}

It can be concluded that non-fouling PDA-PEO surfaces completely inhibited the adhesion and growth of vascular endothelial CPAE cells. Cell adhesion and growth could be restored by functionalizing these surfaces with RGD, a collagen-derived peptide QRQVVGLOGQRGERGFOGLOG-NH $\mathrm{NH}_{2}$ (Col) responsible for collagen-fibronectin interaction and a combination of these ligands in a concentration of $700 \mathrm{fmol} / \mathrm{cm}^{2}$. On surfaces with a combination of RGD + Col ligands, the stability of cell adhesion under a dynamic load was remarkably higher than on the reference polystyrene dishes, on glass coverslips and on surfaces with pure RGD or pure Col, and this stability correlated with the highest expression of talin. Thus a combination of RGD + Col at the higher peptide concentration seems to be the most appropriate way to modify biomaterials, e.g. vascular prostheses.

However, at a lower concentration of these ligands $\left(90 \mathrm{fmol} / \mathrm{cm}^{2}\right)$, the cell colonization in early culture intervals (day 1-3) was noticeably improved only on the RGDbearing surfaces. On surfaces with Col or RGD + Col, this happened only at later culture intervals (day 3-7). This may be due to the expression of different types of integrin receptors in the cells in early and late culture intervals. In addition, the cell performance on surfaces with a lower peptide concentration was generally worse on the surfaces with RGD + Col than on the surfaces with Col alone. This could be explained by simultaneous or competitive binding of RGD and Col ligands to the same integrin receptor, which could alter the signal delivered to the cells and weaken the cell response.

Acknowledgments This study was supported by the Grant Agency of the Czech Republic (Grant No: P108/11/1857 and P108/12/1168), by the Ministry of Education, Youth and Sports of the Czech Republic (Grant Number: EE2.3.30.0029), and by the BIOCEV-Biotechnology and Biomedicine Centre of the Academy of Sciences and Charles University Project (CZ.1.05/1.1.00/02.0109), supported by the European Regional Development Fund. Mr. Robin Healey (Czech Technical University, Prague) is gratefully acknowledged for his language revision of the manuscript.

Open Access This article is distributed under the terms of the Creative Commons Attribution 4.0 International License (http://crea tivecommons.org/licenses/by/4.0/), which permits unrestricted use, distribution, and reproduction in any medium, provided you give appropriate credit to the original author(s) and the source, provide a link to the Creative Commons license, and indicate if changes were made.

\section{References}

1. Bacakova L, Filova E, Parizek M, Ruml T, Svorcik V. Modulation of cell adhesion, proliferation and differentiation on materials designed for body implants. Biotechnol Adv. 2011;29: 739-67.

2. Bacakova L, Filova E, Rypacek F, Svorcik V, Stary V. Cell adhesion on artificial materials for tissue engineering. Physiol Res. 2004;53:S35-45.

3. Prime KL, Whitesides GM. Adsorption of proteins onto surfaces containing end-attached oligo(ethylene oxide)—a model system using self-assembled monolayers. J Am Chem Soc. 1993;115: 10714-21.

4. Statz AR, Meagher RJ, Barron AE, Messersmith PB. New peptidomimetic polymers for antifouling surfaces. J Am Chem Soc. 2005;127:7972-3.

5. Li G, Cheng G, Xue H, Chen S, Zhang F, Jiang S. Ultra low fouling zwitterionic polymers with a biomimetic adhesive group. Biomaterials. 2008;29:4592-7.

6. Pop-Georgievski O, Rodriguez-Emmenegger C, de los Santos PA, Proks V, Brynda E, Rypacek F. Biomimetic non-fouling surfaces: extending the concepts. J Mater Chem B. 2013;1: 2859-67.

7. Pierschbacher MD, Ruoslahti E. Cell attachement activity of fibronectin can be duplicated by small synthetic fragments of the molecule. Nature. 1984;309:30-3.

8. Lowe AB. Thiol-ene "click" reactions and recent applications in polymer and materials synthesis. Polym Chem. 2010;1:17-36.

9. Rostovtsev VV, Green LG, Fokin VV, Sharpless KB. A stepwise Huisgen cycloaddition process: copper(I)-catalyzed regioselective "ligation" of azides and terminal alkynes. Angew Chem Int Ed. 2002;41:2596-9.

10. Dawson P, Muir T, Clark-Lewis I, Kent S. Synthesis of proteins by native chemical ligation. Science. 1994;266:776-9.

11. Mann BK, Tsai AT, Scott-Burden T, West JL. Modification of surfaces with cell adhesion peptides alters extracellular matrix deposition. Biomaterials. 1999;20:2281-6.

12. Mann BK, Schmedlen RH, West JL. Tethered-TGF-beta increases extracellular matrix production of vascular smooth muscle cells. Biomaterials. 2001;22:439-44.

13. Lee H, Dellatore SM, Miller WM, Messersmith PB. Mussel-inspired surface chemistry for multifunctional coatings. Science. 2007;318:426-30.

14. Pop-Georgievski O, Neykova N, Proks V, Houdkova J, Ukraintsev E, Zemek J, Kromka A, Rypacek F. Polydopaminemodified nanocrystalline diamond thin films as a platform for biosensing applications. Thin Solid Films. 2013;543:180-6.

15. Pop-Georgievski O, Verreault D, Diesner MO, Proks V, Heissler S, Rypacek F, Koelsch P. Nonfouling poly(ethylene oxide) layers end-tethered to polydopamine. Langmuir. 2012;28:14273-83.

16. Pop-Georgievski O, Popelka S, Houska M, Chvostova D, Proks V, Rypacek F. Poly(ethylene oxide) layers grafted to dopaminemelanin anchoring layer: stability and resistance to protein adsorption. Biomacromolecules. 2011;12:3232-42.

17. Pierschbacher MD, Ruoslahti E. Variants of the cell recognition site of fibronectin that retain attachment-promoting activity. Proc Natl Acad Sci USA. 1984;81:5985-8.

18. Erat MC, Slatter DA, Lowe ED, Millard CJ, Farndale RW, Campbell ID, Vakonakis I. Identification and structural analysis of type I collagen sites in complex with fibronectin fragments. Proc Natl Acad Sci. 2009;106:4195-200.

19. Proks V, Jaros J, Pop-Georgievski O, Kucka J, Popelka S, Dvorak P, Hampl A, Rypacek F. "Click \& seed" approach to the biomimetic modification of material surfaces. Macromol Biosci. 2012;12:1232-42. 
20. Macková H, Proks V, Horák D, Kučka J, Trchová M. Magnetic poly(N-propargylacrylamide) microspheres: preparation by precipitation polymerization and use in model click reactions. J Polym Sci Pol Chem. 2011;49:4820-9.

21. Dalsin JL, Lin LJ, Tosatti S, Voros J, Textor M, Messersmith PB. Protein resistance of titanium oxide surfaces modified by biologically inspired mPEG-DOPA. Langmuir. 2005;21:640-6.

22. Proks V, Brus J, Pop-Georgievski O, Vecernikova E, Wisniewski W, Kotek J, et al. Thermal-induced transformation of polydopamine structures: an efficient route for the stabilization of the polydopamine surfaces. Macromol Chem Phys. 2013;214:499-507.

23. Popelka Š, Houska M, Havlíková J, Proks V, Kučka J, Šturcová A, et al. Poly(ethylene oxide) brushes prepared by the "grafting to" method as a platform for the assessment of cell receptorligand binding. Eur Polym J. 2014;58:11-22.

24. Humphries JD, Wang P, Streuli C, Geiger B, Humphries MJ, Ballestrem C. Vinculin controls focal adhesion formation by direct interactions with talin and actin. J Cell Biol. 2007;179: 1043-57.

25. Bacakova L, Filova E, Kubies D, Machova L, Proks V, Malinova V, Lisa V, Rypacek F. Adhesion and growth of vascular smooth muscle cells in cultures on bioactive RGD peptide-carrying polylactides. J Mater Sci Mater Med. 2007;18:1317-23.

26. Homola J, Dostalek J, Chen SF, Rasooly A, Jiang SY, Yee SS. Spectral surface plasmon resonance biosensor for detection of staphylococcal enterotoxin B in milk. Int $\mathrm{J}$ Food Microbiol. 2002;75:61-9.

27. Bouaidat S, Berendsen C, Thomsen P, Petersen SG, Wolff A, Jonsmann J. Micro patterning of cell and protein non-adhesive plasma polymerized coatings for biochip applications. Lab Chip. 2004;4:632-7.

28. Roosjen A, Kaper HJ, van der Mei HC, Norde W, Busscher HJ. Inhibition of adhesion of yeasts and bacteria by poly(ethylene oxide)-brushes on glass in a parallel plate flow chamber. Microbiology. 2003;149:3239-46.

29. Hsiue GH, Lee SD, Chang PCT. Platelet adhesion and cellular interaction with poly(ethylene oxide) immobilized onto silicone rubber membrane surfaces. J Biomater Sci Polym Ed. 1996; 7:839-55.

30. Klenkler BJ, Dwivedi D, West-Mays JA, Sheardown H. Corneal epithelial cell adhesion and growth on EGF-modified aminated PDMS. J Biomed Mater Res A. 2010;93A:1043-9.

31. Shiels SM, Solomon KD, Pilia M, Appleford MR, Ong JL. BMP2 tethered hydroxyapatite for bone tissue regeneration: coating chemistry and osteoblast attachment. J Biomed Mater Res A. 2012;100A:3117-23.

32. Frith JE, Mills RJ, Cooper-White JJ. Lateral spacing of adhesion peptides influences human mesenchymal stem cell behaviour. J Cell Sci. 2012;125:317-27.

33. Xiong JP, Stehle T, Zhang RG, Joachimiak A, Frech M, Goodman SL, Arnaout MA. Crystal structure of the extracellular segment of integrin alpha V beta 3 in complex with an Arg-GlyAsp ligand. Science. 2002;296:151-5.

34. Massia SP, Hubbell JA. An RGD spacing of $440 \mathrm{~nm}$ is sufficient for integrin alpha $\mathrm{V}$ beta 3-mediated fibroblast spreading and 140 $\mathrm{nm}$ for focal contact and stress fiber formation. J Cell Biol. 1991;114:1089-100.

35. Cavalcanti-Adam EA, Volberg T, Micoulet A, Kessler H, Geiger B, Spatz JP. Cell spreading and focal adhesion dynamics are regulated by spacing of integrin ligands. Biophys $\mathrm{J}$. 2007;92:2964-74.

36. Huang J, Grater SV, Corbellinl F, Rinck S, Bock E, Kemkemer R, Kessler H, Ding J, Spatz JP. Impact of order and disorder in RGD nanopatterns on cell adhesion. Nano Lett. 2009;9:1111-6.

37. Wang X, Yan C, Ye K, He Y, Li Z, Ding J. Effect of RGD nanospacing on differentiation of stem cells. Biomaterials. 2013;34:2865-74.

38. Glukhova MA, Koteliansky VE. Integrins, cytoskeletal and extracellular matrix proteins in developing smooth muscle cells of human aorta. In: Mecham SM, Schwartz RP, editors. The vascular smooth muscle cell. San Diego: Academic Press; 1995. p. 37-79.

39. Reinmuth N, Liu WB, Ahmad SA, Fan F, Stoeltzing O, Parikh AA, Bucana CD, Gallick GE, Nickols MA, Westlin WF, Ellis LM. Alpha(v)beta(3) Integrin antagonist S247 decreases colon cancer metastasis and angiogenesis and improves survival in mice. Cancer Res. 2003;63:2079-87.

40. Kokubo T, Uchida H, Choi ET. Integrin alpha(v)beta 3 as a target in the prevention of neointimal hyperplasia. J Vasc Surg. 2007;45:33A-8A.

41. Mizuno M, Kuboki Y. Osteoblast-related gene expression of bone marrow cells during the osteoblastic differentiation induced by type I collagen. J Biochem. 2001;129:133-8.

42. Xiao Q, Zeng L, Zhang Z, Hu Y, Xu Q. Stem cell-derived Sca$1(+)$ progenitors differentiate into smooth muscle cells, which is mediated by collagen IV-integrin alpha(1)/beta(1)/alpha(v) and PDGF receptor pathways. Am J Physiol Cell Physiol. 2007;292:C342-52.

43. Ginsberg MH, Partridge A, Shattil SJ. Integrin regulation. Curr Opin Cell Biol. 2005;17:509-16.

44. Chen AK, Delrio FW, Peterson AW, Chung K-H, Bhadiraju K, Plant AL. Cell spreading and proliferation in response to the composition and mechanics of engineered fibrillar extracellular matrices. Biotechnol Bioeng. 2013;110:2731-41.

45. Zimmermann L, Peterhans E, Frey J. RGD motif of lipoprotein T, involved in adhesion of Mycoplasma conjunctivae to lamb synovial tissue cells. J Bacteriol. 2010;192:3773-9.

46. Benoit DSW, Anseth KS. The effect on osteoblast function of colocalized RGD and PHSRN epitopes on PEG surfaces. Biomaterials. 2005;26:5209-20. 